\author{
Asian Journal of Economic Modelling \\ $\operatorname{ISSN}(e): \quad 2312-3656$ \\ $\operatorname{ISSN}(p): \quad 2313-2884$ \\ DOI: 10.18488/journal.8.2018.63.274.286 \\ Vol. 6, No. 3, 274-286 \\ (C) 2018 AESS Publications. All Rights Reserved. \\ URL: wwrwaessweb.com
}

\title{
AN APPLICATION OF CAN SLIM INVESTING IN THE DOW JONES BENCHMARK
}
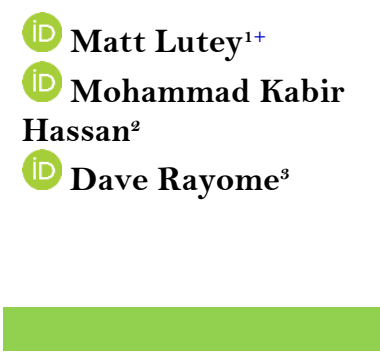

\author{
${ }^{\prime}$ University of New Orleans 1511 Pressburg St. New Orleans, LA 70122, USA \\ Email:matthtey@icloud.com \\ ${ }^{2}$ University of New Orleans, USA \\ Email:mhassan@uno.edu \\ ${ }^{3}$ Northern Michigan University, USA \\ Email:dravome@nmu.edu \\ (+ Corresponding author)
}

\section{Article History \\ Received: 11 December 2018 Revised: 20 April 2018 Accepted: 8 May 2018 Published: 24 May 2018 \\ Keywords: \\ Investing, Investment strategy CAN SLIM Dow Jones industrial average Benchmark tracking Trading}

JEL Classification: C12, C53.
This paper provides an alternative view of the popular CAN SLIM investing strategy by modifying and weighting the criterion. The modified criterion is used to build a portfolio in each of three overlapping time frames. The results of the study are compared to a Dow Jones Industrial Average benchmark over the same time frame and is evaluated on a risk adjusted basis. The study finds that the system outperforms the market on a risk adjusted basis in all three time frames and holds a high $\mathrm{R}$ Squared for each timeframe. The null hypothesis for the majority of this paper is to test whether the mean returns of the strategy are significantly different from zero on a monthly basis. This is tested over three overlapping timeframes of five years, ten years and sixteen years respectively. A further hypothesis is tested for the 2008-2009 timeframe and is whether the mean excess returns of the strategy are significantly different from zero when compared to the Dow Jones benchmark. This paper finds that the null hypothesis is rejected over all time frames with strong evidence. An exception is the 16-year time frame where the null is rejected with weak evidence.

Contribution/ Originality: This study opens the literature on CAN SLIM to include hypothesis testing on the Dow Jones Industrial Average benchmark. It includes empirical testing using methodology from the O'Neil and William (1988) text. It can be applied to other benchmarks and time series.

\section{INTRODUCTION}

The CAN SLIM system is a checklist system based on William O'Neil's study of the best performing stocks dating back to 1953. It is popularized in his book How to Make Money in Stocks: A Winning System in Good Times or Bad. The purpose of this paper is to test whether a modified version of the CAN SLIM system will still produce superior returns over the Dow Jones industrial average over three overlapping time frames.

Risk metrics of Sharpe, Standard Deviation, Beta, R Squared and Maximum drawdown are analyzed in determining which system is better per unit of risk in each overlapping study. Furthermore, confidence intervals are determined using a Z-score test statistic at the 95 percent level of significance to analyze two separate hypotheses: 1) whether the mean returns of the model on a monthly basis are significantly different from zero and, 2) whether the excess return of the model versus the benchmark is significantly different from zero for the period January 2008 - January 2009. 
The modified system is created from a ranking algorithm that places different weight emphasis on the CAN SLIM criteria. A portfolio is constructed of 10 holdings with ideally equal weight. A stop loss is used to keep initial losses small and is rebalanced monthly. More technical details regarding trading fees, management fees and initial starting capital are outlined in a later section of the paper.

Each portfolio is constructed in time zero $(\mathrm{t}=0)$ and simulated on a monthly basis until the end of the period. A five-year study from (2010-2015), ten-year study (2005-2015) and 16-year study (1999-2015) are all tested independently. An isolated one year (2008-2009) study is also tested.

The time frames for 1999-2015 are chosen to incorporate both bull and bear markets. Outlined in Federal Reserve Bank of St. Louis (FRED), are 2001-2002, 2008-2009. Bull markets are 2010-2015. The longer term study is broken in to overlapping time frames (2005-2015), and (2010-2015).

The purpose is to break up the initial study to different start dates with the same end date. To see how different portfolio positions are selected at different time periods, the survival of different stocks over those time frames and also, the risk adjusted returns.

\subsection{Hypothesis}

The null hypothesis for the majority of this study is the returns of the strategy on a monthly basis are equal to zero. The alternative hypothesis is that they are significantly different from zero. This is tested using a Z-score as the test statistic and a confidence interval of 95 percent. This is explained in greater detail in a later section of the paper titled Hypothesis Testing Revisited.

An additional hypothesis is for the 2008-2009 isolated timeframe with the null being whether excess return of the model over the benchmark, during the 12-month period, is equal to zero. The alternative is whether the excess return is significantly different from zero. This is also tested at the 95 percent level of significance.

The purpose is to determine at what level of confidence an investor can expect to receive abnormal returns in the market. (Returns that differ from zero on a monthly basis.) Due to the high standard deviation among returns in the longer time frame, a test statistic or critical value is determined using a null hypothesis that the mean returns are equal to zero. If the null hypothesis is set that the mean returns are some other value larger than zero, it is inconclusive whether the study produces abnormal returns.

\subsection{Significance of CAN SLIM Study}

The following two sections provide examples of independent studies, which use a similar CAN SLIM method of achieving excess returns in the market. A 2008 Study by the College of Business at East Carolina University found that the American Association of Individual Investors (AAII) ran a CAN SLIM Screen with a \$50,000 dollar initial investment which, over 8 years, returned \$430,004, 760.01 percent cumulative return and 30.86 percent annual compound return. This provides evidence that the CAN SLIM system has a track record of achieving excess returns relative to a major benchmark index.

\subsection{CAN SLIM Methodology}

C - Current Earnings. Current earnings should be up 25 percent from the same quarter one year prior. This accounts for accelerating growth in the most recent quarters. It is suggested by the Investor's Business Daily (IBD) strategy that increasing Earnings-Per-Share (EARNINGS PER SHARE) growth in the most recent quarter is a key indicator for future success or growth of the company.

A - Annual Earnings. Annual Earnings should be up 25 percent or more in each of the last three years. Additionally, annual return on equity should be 17 percent or more. This accounts for stability of earnings and is an additional consideration for determining companies that are poised for future expansion. 
$\mathrm{N}$ - New Product or service refers to the idea that a company should have a new basic idea that will fuel earnings growth. This is a qualitative criterion that is somewhat hard to simulate but the IBD system is based on individual selection of securities based on the seven letter acronym as a checklist. Thus, it is not necessarily meant to be automated by a machine.

$\mathrm{S}$ - Supply and demand. An index of a stock's demand can be seen by the trading volume of a stock. Some of the available information on this strategy suggests buying stocks that have at least 100,000 shares traded in average monthly volume, or looking for the volume trend to increase as price increases.

L - Leader or laggard? O’Neil suggests buying "the leading stock in a leading industry." This can be measured by the Relative Price Strength Rating (RPSR) of the stock, an index designed to measure the price of stock over the past 12 months in comparison to the rest of the market based on the S\&P 500 over a set period of time.

I - Institutional sponsorship refers to the ownership of stock by mutual funds, particularly in recent quarters. Increasing fund sponsorship can be a positive signal for potential price movement as large funds tend to move the market or a particular stock like a surfer catching a big wave. It is easier to get on a winning trade supported by a lot of money.

M - Market indexes, particularly the Dow Jones, S\&P 500, and NASDAQ, should be in confirmed uptrends in the three indices. Most stocks tend to follow the general market pattern. IBD uses accumulation or distribution days to determine market direction. It is based on the closing price being greater than 0.20 percent above the previous day's closing price and then resetting after a period of $n$ weeks, usually 5-7 depending on market conditions. Once five distribution days (reverse of accumulation, or stock price close down 0.20 percent below the previous trading day) have been counted within a given time frame, the market is no longer in a confirmed uptrend.

\section{LITERATURE REVIEW}

Sweeney (1988) note that filter rules have been used in academic research since (Fama and Marshall, 1966) who looked at the Dow 30 of the late 1950 s and found that after adjusting for transaction costs, no profits remained for the best (1/2-percent) rule of that time.

Givoly and Lakonishok (1979) note that evidence shows that earnings possess information value, and the observed stock price reaction to an earnings announcement continues over several weeks or months after the announcement.

Gilette (2005) compared a modified version of the CAN SLIM system on the German exchange. The criteria used a version of EARNINGS PER SHARE to account for current and annual earnings and used relative strength for the leader/laggard criterion. The study found no conclusive evidence to support the significance of returns using this strategy. It did however find some promise for including the $\mathrm{N}$ in CANSLIM which was interpreted as picking stocks making a new high rather than new product service or management and including a stop loss for money management. The study did find that adding the $\mathrm{N}$ and a stop rule from O'Neil's system produced a mean compound return of 10.98 percent with 99 percent confidence from 1985-2005. This study relates to the CAN SLIM method outlined in this paper in that it tests the excess returns over the benchmark index with strong levels of confidence (alpha $=0.01$ ). It also is significant in that it examines the significance or importance of different criteria. For example, using the $\mathrm{C}$ and $\mathrm{L}$ alone do not produce significant results but adding the $\mathrm{N}$ and a stop loss provide excess returns in the market.

A study by Deboeck (2000) showed that the CAN SLIM criteria when benchmarked against the S\&P 500 produced superior results when the criterion are weighted or clustered. This study provides evidence that adding different levels of significance to the CAN SLIM criteria can produce excess returns in the market. A similar study by Debuck concludes that equally weighting all seven criterions does not produce any results but that weighting the criterion will provide excess returns in the overall market. . The purpose of this study is to see whether a modified version of the strategy will produce excess returns when benchmarked against the Dow Jones index. 
A 2013 study by Lutey et al. found that a modified version of the CAN SLIM system performed with superior results benchmarked against the S\&P500. The study was based primarily on Current and Annual earnings per share which outperformed the S\&P 500 by 0.82 percent per month from 2001 to 2012 and amounted to 700 percent total return over the time frame with 90 percent confidence of superior returns in excess of the market. This study uses similar methodology to this paper but does not create a ranking or weighting algorithm. It uses slimmed down criteria as a stock filter or screen and randomly selects positions to fill the portfolio based on those that pass the initial screen.

Lutey et al. (2014) showed a version of the CAN SLIM system benchmarked against the Nasdaq 100 which produced a 604.34 percent return from 1999-2013 compared with the Nasdaq 100 return of 73.41 percent. The study used the $\mathrm{C}$ and $\mathrm{A}$ along with a stop loss. This paper uses a ranking algorithm and adds a stop-loss which is more closely related to the methodology in this paper.

According to O'Neil and Ryan (1988) the majority of the market's biggest winners have a positive relationship between increasing profits and increasing stock price. Examples include: Cisco which posted earnings per share gains of 150 percent and 155 percent in the two quarters ending October 1990, prior to a 1,467 percent breakout over the next three years. Accustaff similarly showed a 300 percent profit increase just before its price gain of 1,486 percent in the 16 months after January 1995. Ascend Communications saw earnings increase of 1,500 percent in August 1994, prior to its 1,380 percent price move over the next 15 months.

O’Neil and Ryan (1988) states that none of the criteria stand out as boldly as the profits each big winner reported in the latest quarter or two before its major price advance. In WJO's models of the 600 best-performing stocks from 1952 to 2001, three out of four showed earnings increases averaging more than 70 percent in the quarter before they began their major advances. The remaining 25 percent did so the very next quarter and had average earnings increase of 90 percent.

In terms of the $\mathrm{C}$ in CAN SLIM this refers to picking a stock that has a major increase in quarterly EARNINGS PER SHARE in the most recent quarter when compared to the same quarter one year prior; further justification for the ranking method of EARNINGS PER SHARE rather than a strict screen and random selection.

\section{METHODOLOGY}

This paper uses the Current, Annual, Leader, and Institutional Sponsorship of CAN SLIM. New product, service or highs is not accounted for and is hard to quantify but is done by an independent study referenced in the bibliography. This is referenced in comparison to previous versions of the paper by Lutey et al. (2013) which use a modified CAN SLIM system using the current and annual earnings criteria to determine whether the model provides significantly greater returns than the benchmark S\&P 500 over three independent timeframes. Also, Lutey et al. (2014) run the CAN SLIM strategy benchmarked on the Nasdaq 100 and account for Current, Annual and Institutional Sponsorship of the CAN SLIM strategy. No study so far has accounted for the M or market direction, or the Dow Jones Industrial average by the same research group. Thus, this paper looks to implement new ideology in the CAN SLIM strategy by accounting for new criteria and considering new risk-adjusted measures. Previously, total return, annual return, Sharpe, maximum draw down and standard deviation were considered. In this paper, $\mathrm{R}$ squared and beta are added to the mix. Also, hypothesis testing is more comprehensively considered. Furthermore, this paper implements a hedge to test for market direction using an average directional index and runs a hypothesis test on the returns. Lastly, the 2008-2009 timeframe is isolated and tested for significance of returns. This is unique to this study. Some papers consider self-organizational mapping to provide weights to the CAN SLIM criteria due to the highly subjective nature of the system. This paper uses similar methodology in weighting the criteria and ranking stocks which possess the CAN SLIM method.

This paper uses a modified version of the CAN SLIM strategy via a ranking system that places different weights to the different letters in the acronym. Greatest emphasis given to the current and annual earnings of CAN 
SLIM, as well as institutional sponsorship. Leader or laggard is accounted for by placing similar weights to industries. Current earnings are accounted for as an industry weight in the form of earnings per share (EPS) percent change prior quarter, earnings per share growth as a percentage change versus the same quarter one year prior. This is weighted for stocks relative to their own industry, stocks with the highest-growth in the current quarter are given top priority. The next selection criteria earnings per share three-year average this is basically seeking companies with eps three-year average within their own industry with top priority given to the companies with the greatest three-year average. This provides for the current and annual earnings components of CAN SLIM. Institutional Shares Owned is weighted based on stocks relative to the universe, in this case the universe is limited to the Dow Jones and this accounts for the institutional ownership component in CAN SLIM. The next bit of criteria is narrow and is a modified way of searching for leaders based on industry data. That stocks are previously ranked relative to other stocks in their own industry, now industries are weighted against other industries so the algorithm is essentially picking the top stocks in top industries rather than using an Investor's Business Daily (IBD) relative strength method the system is further modified to account for the leader or laggard component.

\subsection{Ranking System}

The CAN SLIM criteria are ranked in this study, as compared to previous studies that use filter rules (Lutey et al., 2013; Lutey et al., 2014). The purpose of the ranking system is to account for the small number of components on the Dow 30, rather than filtering components that may not meet the specific criteria outlined by O'Neil.

The highest percent is given to Earnings growth versus the same quarter one year prior, within industry; this is followed by earnings growth three-year average within industry, and institutional shareholders within industry comparison. These are weighted at 35 percent, 25 percent and 15 percent respectively.

Further consideration is given to out of industry ranks. Sales percent growth versus the same quarter one year prior is rated highest among the following: Earnings growth versus the same quarter one-year prior, earnings growth three-year average, and sales growth three-year average. The ranks for these out of industry ranks or universe ranks are 10 percent, and five percent for the remaining respectively.

The highest is given to inter-industry to pick the best leading stocks within the industry first. Earnings growth is rated highest for current earnings to support any current three-year trend in growth. Institutional sponsorship is rated the third for strong fund ownership or backing.

\subsection{Portfolio Construction}

One hundred thousand dollar starting capital is used for the fund. The Dow Jones is used as a benchmark for the model. Ideally a portfolio will hold ten positions with a weight of ten percent per position. The model will deviate up to thirty percent from this ideal weight. Positions are randomly selected based on the earlier defined ranking algorithm. A stop of eight percent is used from the entry price. Positions that are stopped out are reconsidered at the next rebalance. Portfolio is rebalanced every four weeks.

\subsection{Trading Fees}

No management fee is considered for this simulation. Commission is ten dollars per entry and exit. Slippage which is defined as the difference between a computer generated entry and exit and where a client with actual money would enter and exit based on the computer's signals (Wikipedia) is fixed at one half of one percent of the total amount. The price considered for each transaction is the next open, and only long transactions are considered. Long transactions are defined by Investopedia as the buying of a security with the expectation that it will rise in value. 


\section{RISK MANAGEMENT}

\subsection{Risk Metrics}

The significance here is to determine if the strategy produces superior returns on a risk-adjusted basis. The Sharpe ratio is the industry standard used in filtering out risk to determine a value of two similar assets with different risk and return. In evaluating Sharpe, average annual return is used. Risk is determined by standard deviation which is defined in the proceeding section. The purpose of evaluating a model or benchmark on a riskadjusted basis is to determine if abnormal returns are generated by taking excess risk.

Evaluating metrics such as portfolio Beta and R squared through linear regression help determine how well the returns of the model fit the returns of the benchmark, and how volatile the portfolio is when compared with the benchmark. Standard deviation is the volatility among the returns of the model and Beta is the risk of the portfolio. These are used together to determine how the portfolio is compared with its benchmark. Maximum drawdown is also considered to determine the maximum loss in one period. A study that accounts for negative value standard deviation and gives a numerical approach to determining the probability of a large loss in any given period is The Sortino ratio. This ratio is not defined in the study but it is noted that the probability of a large loss in any given period should be higher for the benchmark than the model to determine better returns per unit of risk.

The Treynor ratio is used in addition to the Sharpe ratio by replacing standard deviation with portfolio beta. It is noted that the risk metrics for all time frames are lower than that of the benchmark, while the returns (geometric, annual) are greater.

\subsection{Hypothesis Testing}

A test statistic is used from a Z-score table at each of the $90^{\text {th }}, 95^{\text {th }}$, and $99^{\text {th }}$ level of significance. The $95^{\text {th }}$ percentile is the standard for strong supporting evidence. $90^{\text {th }}$ provides weak supporting evidence. The $\mathrm{Z}$ values for each percentile are as follows: $90^{\text {th }}-1.28,95^{\text {th }}-1.645,99^{\text {th }}-2.33$; this is used along with known information in the study to obtain a critical value based on the equation for $\mathrm{Z}$.

\subsection{Return Metrics}

Annualized Return: Time-weighted annual percentage of returns; sources can include dividends, returns of capital (realized gains) and capital appreciated. The rate of return is measured against the initial amount of the investment and represents a geometric mean rather than a simple arithmetic mean.

Total Return: This is the product of the annualized return stream minus one. This shows the percent return the investment accumulated from inception to culmination.

\section{RESULTS}

The study evaluated over three overlapping time frames. Risk measures outlined above are evaluated, along with a null hypothesis of Ho = zero. Each time frame has a separate and portfolios, constructed at the start date. All time frames are evaluated through January 2015.

A five year time frame, starting January 2010 and ending January 2015 is evaluated first, along with a ten year time frame (January 2005 - January 2015) and a sixteen year time frame (January 1999 - January 2015). Each period has overlapping and separate results based on different market conditions. All are constructed using the same buy signals and stop loss; and are evaluated using the same measures of risk and null hypothesis. 


\subsection{Graphs}

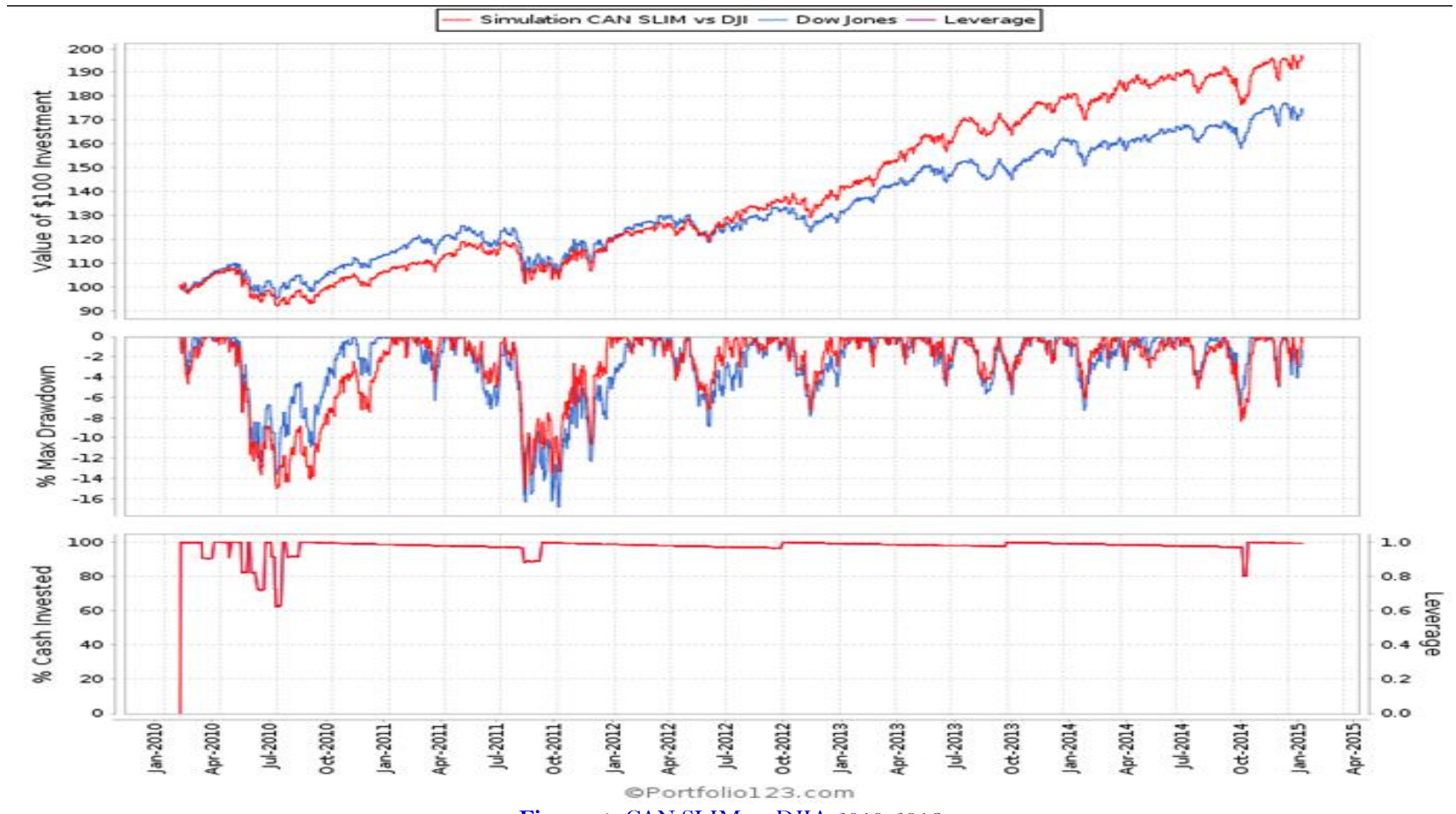

Figure-1. CAN SLIM vs DJIA 2010-2016

Source: Portfolio123.com

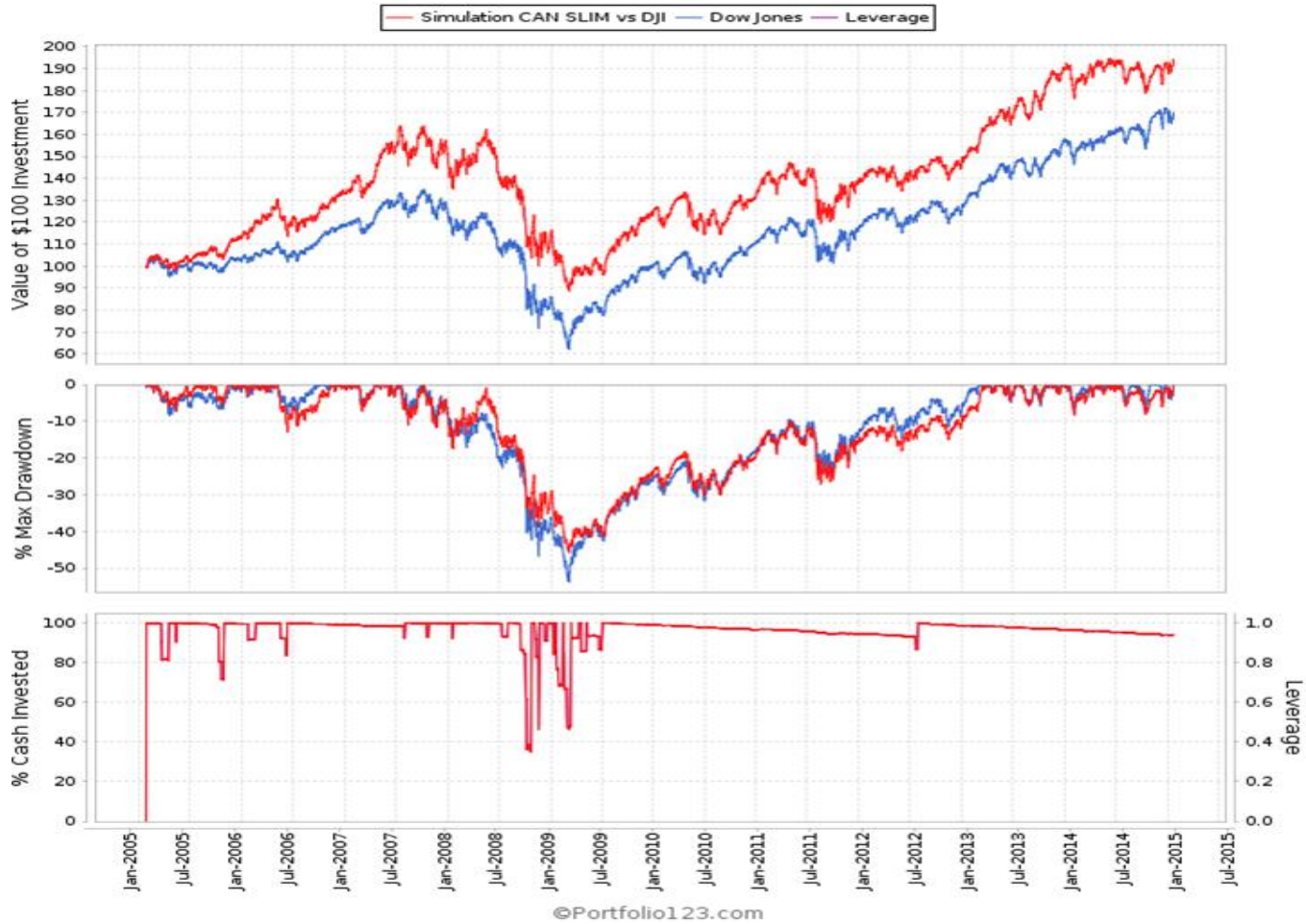

Source: Portfolio123.com

Figure-1. CAN SLIM vs DJIA $2005-2015$ 


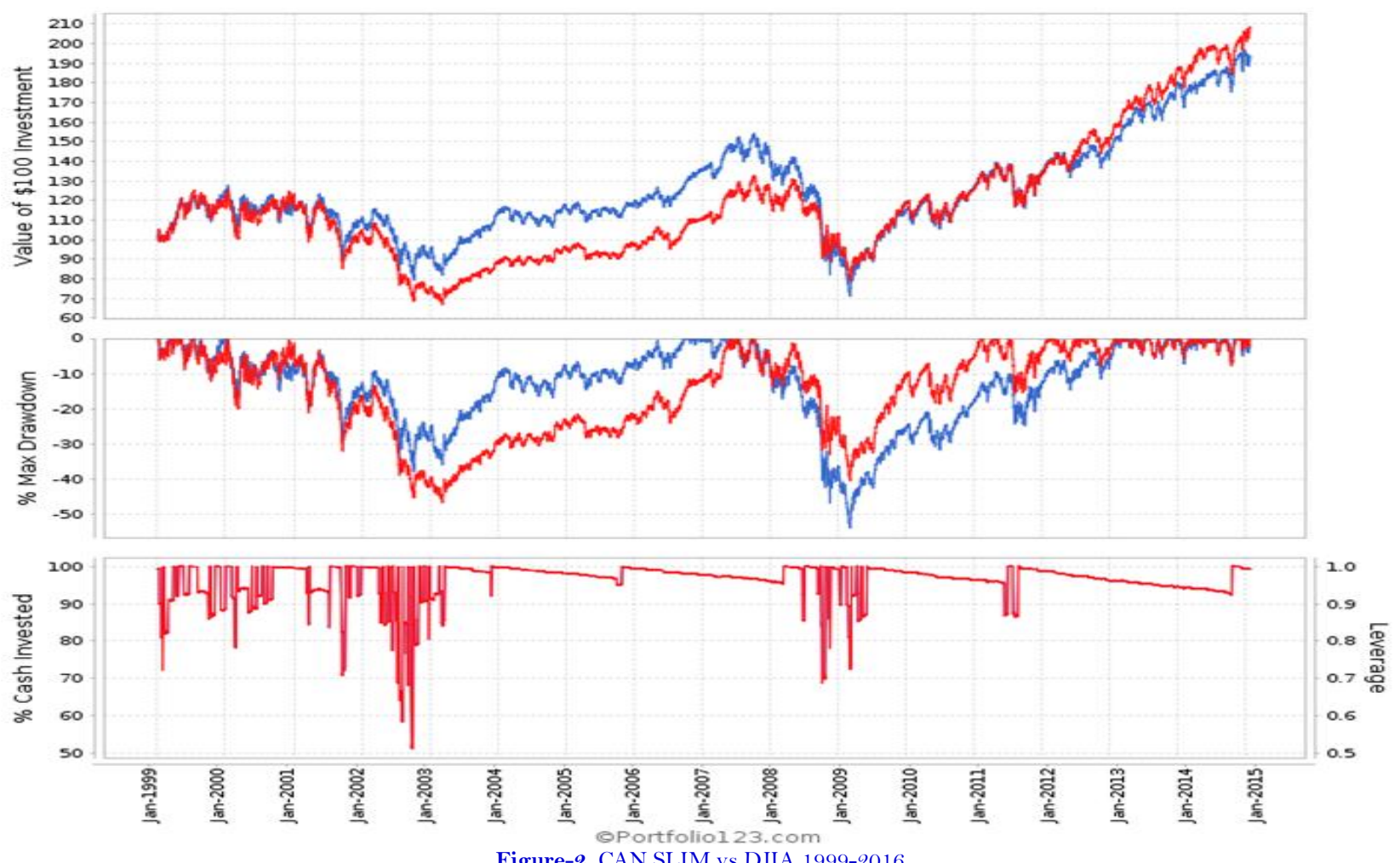

Source: Portfolio123.com

Figure-2. CAN SLIM vs DJIA 1999-2016

This shows the portfolio return, maximum drawdown and cash invested for all portfolios. They are overlapping time frames from January 1999 - January 2015.

It is interesting the portfolio reduces exposure in down markets despite not having any specific rule for down markets. This is due to the stop loss and waiting to re-enter the market. Or, having no eligible stocks to fill the portfolio in down markets.

\subsection{Portfolio Results}

Five Year: 2010-2015

Standard Deviation: The model has a lower standard deviation of 13.96 when compared to the benchmark of 14.57. This suggests that the model has a lower volatility or dispersion among annual returns than that of the benchmark. This suggests lower total risk.

Sharpe: Risk-Adjusted return is greater than that of the benchmark. That is, per unit of risk the model has a greater unit of return. This shows that per unit of standard deviation and accounting for the riskless rate of return (T-Bill) the strategy performs better than the benchmark.

Maximum Drawdown: The maximum draw down of the model is lower than that of the benchmark. Less negative, therefore it has lower total downside risk.

R-Squared: Measure of good fit. 0.90 suggests that the returns of the model are highly correlated or dependent upon/determined by the returns of the benchmark.

Beta: Less than 1.0 at 0.91 indicates slightly less portfolio risk than the overall market. Another measure of volatility which indicates less risk than the market, suggesting a better strategy than a buy and hold method.

Total Return: $95.44 \%$ in the model versus $73.31 \%$ in the benchmark. Higher total return is accompanied by a lower standard deviation and higher Sharpe ratio indicating better return per unit of risk.

Annual Return: $14.36 \%$ versus $11.64 \%$. This indicates a better return annually than the benchmark. One can subtract the model average return from that of the benchmark to determine the annualized alpha. This amount comes to be $3.45 \%$ per year. 
From this data it is evident that the system is a better performer per unit of risk, has superior performance on a total return and annual return basis and has lower maximum draw down and lower volatility, lower beta and has a high $\mathrm{R}$ squared, indicating the returns of the model can be determined by the returns of the benchmark. At the $95 \%$ significance level the system cannot conclude that the excess returns of the model are significantly different from zero when compared to the market but can determine however that the model returns on a monthly basis are significantly different from zero. This suggests that the model does produce some positive return on a monthly basis over a five year period. The null hypothesis in this scenario is zero and the alternative is the tested monthly return of $0.90 \% /$ month which is significant at $95 \%$. Thus, there is strong evidence suggesting the strategy will produce $0.90 \% /$ month over a five-year period.

Ten Year: 2005-2015

Standard Deviation: $18.06 \%$ Model, versus 18.75\% Dow Jones indicates lower volatility among the returns. This indicates lower risk than the benchmark.

Sharpe: Sharpe ratio in this study is greater than that of the Dow Jones, indicating better unit of return per unit of risk. 0.19 compared with 0.11 , this is a better strategy on a risk-adjusted basis.

Maximum Drawdown: $-45.77 \%$ compared to $-53.78 \%$. The system does not drop as low as the benchmark in a major sell-off. The system has less total downside.

R-Squared: $86 \%$ of the returns of the model are explained by the benchmark.

Beta: 0.89 which is lower than 1.0 indicating lower total portfolio risk than the market.

Total Return: $92.56 \%$ versus $68.33 \%$. The model has a higher total return than the benchmark. Annual Return: $6.78 \%$ versus $5.35 \%$. This could lead to an annualized alpha of $1.43 \%$; which is only as significant as the hypothesis testing considers when the returns are normalized.

Sixteen Year: 1999-2015

Standard Deviation: Model standard deviation of 18.16 compared with the benchmark of 18.85. This lower standard deviation indicates lower volatility among returns and can conclude that the system has lower risk than a buy and hold strategy with the benchmark.

Sharpe: Sharpe ratio is 0.04 compared with 0.01 of the benchmark indicating better expected reward per unit of risk.

Maximum Drawdown: -46.59 versus $53.78 \%$. This is the same as the ten-year period and is likely due to the major 2008 sell off. The benchmark provides a buy and hold strategy holding positions to the bottom of the market decline.

R-Squared: 0.88 percent which indicates that the model are 88 percent explained by the returns of the benchmark.

Beta: 0.90; less than 1.0 indicating lower risk on the portfolio when compared with the benchmark.

Total Return: $104.55 \%$ versus $92.48 \%$. This shows that the model performs better per total unit of return over the fifteen-year timeframe.

Annual Return: On an annualized basis, the model has a return of $4.56 \%$ compared with the benchmark return of $4.16 \%$.

Reject the null at 90 percent confidence. This provides weak supporting evidence in favor of the alternative hypothesis.

\subsection{Summary}

Each study is better than the benchmark with at least 90 percent significance. Studies of five years and ten years are both better at 95 percent significance. This provides weak evidence (90 percent) and strong supporting evidence (95 percent) that the mean returns of the strategy are better than zero on a monthly basis.

All studies are better unit of reward per unit of risk as evaluated by Sharpe ratio. All three studies have a high R Squared indicating high correlation with the benchmark index. 
Isolating the 2008-2009 timeframe from the longer sixteen-year study provides an interesting view and another null hypothesis. Ho is to test whether the excess return of the strategy over the benchmark is significantly different from zero. This is outlined in the section below.

\begin{tabular}{lrrrrrr} 
& \multicolumn{2}{c}{ Five Year } & \multicolumn{2}{c}{ Ten Year } & \multicolumn{2}{c}{ Sixteen Year } \\
Risk Measures: & Model & Dow Jones & Model & Dow Jones & Model & Dow Jones \\
Standard Deviation & $13.96 \%$ & $14.57 \%$ & $18.06 \%$ & $18.75 \%$ & $18.16 \%$ & $18.85 \%$ \\
Sharpe & $85.00 \%$ & $63.00 \%$ & $19.00 \%$ & $11.00 \%$ & $4.00 \%$ & $1.00 \%$ \\
Treynor & $98.63 \%$ & $0.66 \%$ & $68.26 \%$ & $0.26 \%$ & $49.72 \%$ & $0.18 \%$ \\
& & & & & & \\
Return Measures: & & & & & & \\
Total Return - & $95.44 \%$ & $73.31 \%$ & $92.56 \%$ & $68.33 \%$ & $104.6 \%$ & $92.5 \%$ \\
Annual Return - & $14.36 \%$ & $11.64 \%$ & $6.78 \%$ & $5.35 \%$ & $4.6 \%$ & $4.2 \%$ \\
Average Return & $0.90 \%$ & $0.91 \%$ & $0.61 \%$ & $0.51 \%$ & $0.45 \%$ & $0.43 \%$ \\
Source: Portfolio123.com and Microsoft Excel & & Figure-3. Risk and Return & & &
\end{tabular}

\subsection{Overlapping Timeframe, 2008 Isolated}

This is a study gathered from the monthly data within the 1999-2015 study. This isolates the 2008-2009 timeframe or major recession. Model returns are compared with benchmark returns and excess return of each period is calculated.

Given the returns of both the benchmark and the model are exposed to primarily negative returns in each period, calculating the excess return is appropriate. The hypothesized mean is that the excess return is zero. Alternative hypothesis is excess return is significantly different from zero.

To formulate this hypothesis using a $\mathrm{Z}$ score test statistic, this author calculates the mean and standard deviation of the excess return column and notes the number of months observed. Using the 95 percent significance level or $Z(0.05)=1.645$. Isolating the critical value with known data, it is compared with the mean for the period. If the mean is greater than the critical value, reject the null hypothesis. If not, do not reject the null hypothesis. 90 percent and 99 percent levels of significance are also considered and formulated in the excel table below.

\begin{tabular}{|c|c|c|c|}
\hline & $\mathrm{Ho}=0.00$ & $\mathrm{Ha}>0.00$ & \\
\hline $\begin{array}{c}\text { Decision } \\
\text { Do not }\end{array}$ & $\begin{array}{c}\text { Level of } \\
\text { Significance }\end{array}$ & Critical & \\
\hline Reject & $99 \%$ & 1.49 & \\
\hline Reject & $95 \%$ & 1.05 & \\
\hline Reject & $90 \%$ & 0.82 & \\
\hline$n=13$ & Model & Dow & Excess \\
\hline Mean & -0.02 & -0.04 & $\underline{1.41}$ \\
\hline St Dev & 0.05 & 0.05 & $\underline{2.31}$ \\
\hline
\end{tabular}

Source: Table Created in Excel

Figure-4. 2008-2009 Critical Value

The mean returns are greater than the critical value. This study rejects the null hypothesis that the mean excess return is equal to zero. This provides strong supporting evidence that the mean return of the strategy is better than the benchmark during the 2008-2009 timeframe. 
It is important to know whether the model is dependent upon the benchmark returns during this time frame. A simple linear regression is run between the model return column and benchmark return column to calculate $\mathrm{R}$ squared. If it is high, $(>80)$ one can determine that the model returns are determined by the benchmark. The Rsquared is 0.801 .

$\mathrm{R}$ squared in this case represents that 80 percent of the model returns are determined by the benchmark index during the 2008-2009 timeframe. This high $\mathrm{r}$ squared indicates that the majority of returns in this study are determined by the benchmark index.

\section{CONCLUSION}

Over four overlapping timeframes the modified CAN SLIM strategy provides superior returns per unit of risk when calculating Sharpe, standard deviation, total return and annualized return. Beta and R squared are noted for curiosity and indicate $>80 \%$ of model returns are determined by the benchmark in all time frames and beta is lower than 1.0 for each. The overlapping studies do not conclude that the returns of the system are greater than the benchmark but do conclude with strong evidence in three out of four time frames that the mean monthly returns are greater than zero. An isolated 2008-2009 study indicates that the model returns are significantly greater than that of the benchmark with $95 \%$ confidence. This is a significant result when considering the overlapping longer-term studies failed to produce conclusive result when returns of the model were compared to the benchmark. An alternate 1999-2015 timeframe implemented the $\mathrm{M}$ or market direction criteria, i.e. reducing capital exposure in sideways (ranging) markets and bear markets. The study failed to show that it produced returns that are significantly different from the mean returns of the benchmark but did show with stronger evidence that the means were better than zero on an annual basis. Accounting for market direction is a better play in addition to the modified can slim criteria than not including it. Lastly, the system as a whole provides evidence for generating returns that are significantly different from zero when using the CAN SLIM criteria. For a follow-up version of the paper, one could test whether the standard deviation and mean return of the Dow Jones provide similar information or weak information regarding the validity of returns in excess of zero. This would provide stronger evidence in support of the model system. In previous versions of the paper, Lutey et al. (2013) determined that a similar modified model produced superior returns in excess of the S\&P 500 market with weak evidence 90\% confidence. The purpose of this paper is to 1) provide an update of the methodology, account for new criteria in the CAN SLIM system. 2) isolate the2008-2009 bear market and run hypothesis testing, 3) and test whether the mean returns are significantly different from zero across multiple overlapping time frames. This paper achieved all of the above in testing and concluded that the mean returns can be different from zero. Lastly, the 2008-2009 timeframe can be isolated and tested for strong evidence that the system provides excess returns over the Dow Jones Industrial Average. Lutey et al. (2014) ran an independent study on the CAN SLIM criteria with less selection criteria and no hypothesis testing in evaluating the strategy benchmarked against the Nasdaq 100.The system provides some conclusive evidence that it is better than a buy and hold strategy with the Dow Jones Industrial Average.

Comments on realized transactions: It is evident that the system returns are generated from unrealized gains. The majority of the returns are held in current holdings as there are no rules for taking profit. Dropping from no rank or a merger, or off the buy list are the only ways of realizing a gain. The Stop loss is the majority of the realized transactions. Looking at the current holdings however it is evident that the system is producing superior returns in excess of the market. Later versions of the paper will likely include a method of profit taking to account for a systematic way of locking in returns.

Funding: This study received no specific financial support.

Competing Interests: The authors declare that they have no competing interests.

Contributors/Acknowledgement: All authors contributed equally to the conception and design of the study. 


\section{REFERENCES}

Deboeck, U., 2000. Picking stocks with emergent self-organizing maps: Self-organized findings about the public, institutions and smart investors. Neural Network World. Available from cgfunding.com.

Fama, E.F. and E.B. Marshall, 1966. Filter rules and stock-market trading. Journal of Business, 39(S1): 226-241. View at Google Scholar | View at Publisher

Gilette, 2005. An empirical test of German stock market efficiency. Center for Applied Statistics and Economics; Institute for Statistics and Econometrics.

Givoly, D. and J. Lakonishok, 1979. The information content of financial analysts' forecasts of earnings: Some evidence on semistrong inefficiency. Journal of Accounting and Economics, 1(3): 165-185. View at Google Scholar

Lutey, Crum and Rayome, 2013. Outperforming the broad market: An application of CAN SLIM Strategy. ASBBS e-Journal, 9(1): 90. View at Google Scholar

Lutey, Crum and Rayome, 2014. OPBMII: An application of CAN SLIM strategy. Journal of Accounting and Finance, 14(5): 114.

O'Neil, W., J. and J.O.N. William, 1988. How to make money in stocks. New York: McGraw-Hill, 10.

O’Neil, W.J. and C. Ryan, 1988. How to make money in stocks: A winning system in good times or bad third edition a summary of the original text. Retrieved from Austin8.com.

Sweeney, R.J., 1988. Some new filter rule tests: Methods and results. Journal of Financial and Quantitative Analysis, 23(03): 285300 .

\section{BIBLIOGRAPHY}

Schadler, F.P. and C.D. Brett, 2008. Are the AAII stock screens useful tools for investors? Financial Services Review, 17(3): 185-201. View at Google Scholar

\section{Appendix 1 - Risk Metrics}

Standard Deviation: Measures how much an investment's return varies around its mean.

$\sigma_{p}=\sqrt{\frac{1}{N} \sum_{i=1}^{N}(X i-x)^{2}}$

$\mathrm{N}=$ number of observations

$\mathrm{Xi}=$ observed return

$\mathrm{x}=$ average return

Beta: The market beta is 1.0 by definition. A portfolio beta greater than 1.0 implies it is expected to return more in up markets, and less in down markets. A portfolio beta less than 1.0 implies it is expected to return less in up markets and outperform in down markets.

\section{$\beta=$ (Covariance of Market Return with Stock Return)/(Variance of Market Return)}

R-Squared: In statistics R-squared measures how close data are fitted to a regression line. In finance, it determines how much of the portfolio returns are explained by the market.

The Sharpe Ratio: The industry standard for calculating risk adjusted return. Developed by William F. Sharpe and outlined in his paper in The journal of portfolio management, 1994.

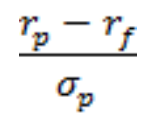


$r_{p}=$ portfolio return

$r_{f}=$ risk free rate of return

$\sigma_{p}=$ standard deviation of portfolio returns

The Treynor Ratio: Another measure of risk adjusted return. Replacing the denominator of the Sharpe ratio with beta.

$\frac{r_{p}-r_{f}}{\beta}$

$\beta=$ Portfolio beta

Total Return: The actual rate of return over the fund duration.

$1-\prod_{i=1}^{N}\left(1+r_{p}\right)$

Geometric Return: Average return that considers compounding interest.

$1-\sqrt[N]{\prod_{i=1}^{N}\left(1+r_{p}\right)}$

Z Test: Determines whether two return streams are statistically different.

$Z=\frac{x-\mu}{\sigma_{m} / \sqrt{N}}$

$\mu=$ average return on the benchmark

$\sigma_{m}=$ standard deviation of benchmark returns 